\title{
NEW GENERATION OF PRODUCTS BY CHEMICAL AND BIOTECHNOLOGICAL APPROACHES Effect of structure of defined triglycerides on the physical properties of fatty bases
}

Oléagineux, Corps Gras, Lipides. Volume 8, Numéro 1, 45-8, Janvier - Février 2001, Dossier : Deutsche Gesellschaft für Fettwissenschaft - Association française pour l'étude des corps gras

Auteur(s) : Vladimír FILIP, Jan SMIDRKAL, Martin STEPANEK, Department of Dairy and Fat Technology, Institute of Chemical Technology, Technická 5, 16628 Praha 6, Czech Republic.

Résumé : Compte tenu du fait que toute transestérification d'huiles et de corps gras donne naissance à un mélange de matières, les structures triglycéridiques suivantes ont été synthétisées : 1,2dicaprinoyl-3-stéaroylglycérol, 1,3-dicaprinoyl-2-stéaroylglycérol, 1,2-dilauroyl-3-stéaroylglycérol, 1,3-dilauroyl-2-stéaroylglycérol, 1,2-dimyristoyl-3-stéaroylglycérol, 1,3-dimyristoyl-2-stéaroylglycérol. Les bases grasses modèles ont été préparées par le brassage de ces triglycérides avec de l'huile de colza à basse teneur en acide érucique, en rapport $\mathrm{m} / \mathrm{m}$ de 15-35 : 85-65\%, et caractérisées par leur point de fusion, point de solidification, proportion des parts solides en fonction de la température (profil SFC) par la méthode RMN et le seuil de contrainte. Les propriétés des bases grasses modèles sont le plus influencées par la symétrie des molécules des triglycérides structurés. L'influence de la masse moléculaire croissante des triglycérides structurés est d'ordre secondaire.

Mots-clés : dicaprinoylstéaroylglycérol, dilauroylstéaroylglycérol, dimyristoylstéaroylglycérol, base grasse, propriétés physiques, triglycéride structuré.

Summary : With respect to the fact that during transesterification of oils and fats the mixture of substances are produced, following defined chemical structures of trisaturated triglycerides were synthesised: 1,2-dicaprinoyl-3-stearoylglycerol, 1,3-dicaprinoyl-2-stearoylglycerol, 1,2-dilauroyl-3stearoylglycerol, 1,3-dilauroyl-2-stearoylglycerol, 1,2-dimyristoyl-3-stearoylglycerol, 1,3-dimyristoyl2-stearoylglycerol. The model fatty bases were prepared by blending of these triglycerides with low erucic rapeseed oil in the ratio $15-35: 85-65 \% \mathrm{w} / \mathrm{w}$ and were characterised by use of the melting point, solidification point, SFC profile (p-NMR) and yield value. The molecule symmetry effect of the structured triglycerides influences the physical properties of the model fatty bases to the greatest measure. The influence of the growing molecular weight of structured triglycerides has secondary influence.

Keywords : dicaprinoylstearoylglycerol, dilauroylstearoylglycerol, dimyristoylstearoylglycerol, fatty base, physical properties, structured triglycerid. 


\section{ARTICLE}

The main component for the manufacture of margarines is the fatty base. In the simplest case, the fatty base consists of a structural fat and liquid oil. Fatty bases of soft margarines contain practically concentration of trans-isomers as low as zero at the present time [1,2]. One of the possible ways of manufacturing structural fat is the transesterification of vegetable oils, for instance fully hydrogenated rapeseed oil [3], fully hydrogenated palm oil, palmstearin [4] and coconut oil [5, 6]. The content of saturated fatty acids in the low-trans fatty bases is then relatively high. The structural fat which was formed by the process of transesterification is always represented by a mixture of individual triglycerides.

For explanation of relations between the structural fat and the properties of the fatty base, it was necessary to prepare defined triglycerides by unambiguous synthesis. Two types of structured triacylglycerols were prepared, 1,2-diacyl-3-stearoylglycerols (unsymmetrical type) and 1,3-diacyl-2stearoylglycerols (symmetrical type) where acyls are the caprinoyl-, lauroyl- and myristoyl-.

\section{Experimental part}

\section{Synthesis of 1,2-diacyl-3-stearoylglycerol}

Stearoylglycerol was prepared by the reaction of isopropylidenglycerol with methylstearate and subsequent degradation of an isopropylidene group [7]. The obtained 1-stearoyglycerol was acylated with acylchloride in pyridine medium to desired symmetrical triacyglycerol [8]. The purity of all prepared triacyglycerols was minimal 98\% (analysed by TLC-FID [11]). 1,2-dicaprinoyl-3stearoylglycerol (CiCiSt), 1,2-dilauroyl-3-stearoylglycerol (LaLaSt) and 1,2-dimyristoyl-3stearoylglycerol (MyMySt) were prepared.

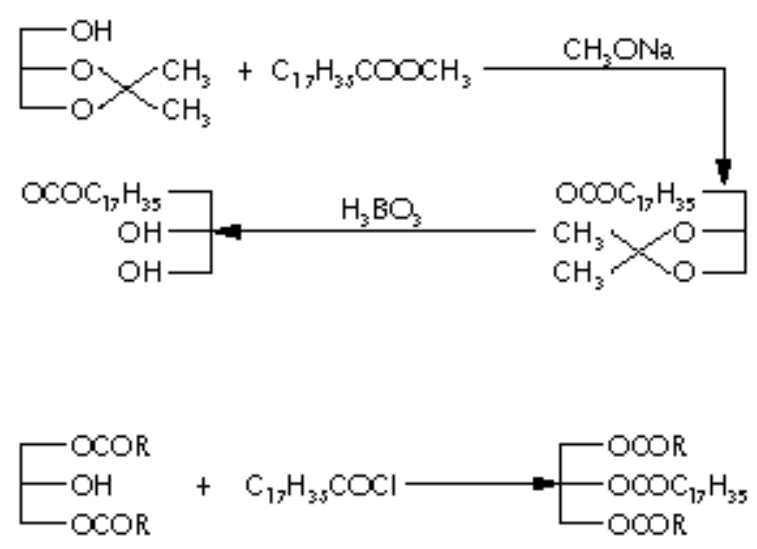

\section{Synthesis of 1,3-diacyl-2-stearoylglycerol}

The initial dihydroxyacetone was acylated with acylchloride in pyridine medium; and 1,3diacylderivative was obtained by subsequent reduction with sodium borohydride to $1,3-$ diacylglycerol, which was acylated by stearoylchlorid to the final 1,3-diacyl-2-stearoylglycerol $[9,10]$. 
The purity of all prepared triacyglycerols was minimal 98\% (analysed by TLC-FID [11]). 1,3dicaprinoyl-2-stearoylglycerol (CiStCi), 1,3-dilauroyl-2-stearoylglycerol (LaStLa) and 1,3-dimyristoyl-2stearoylglycerol (MyStMy) were prepared.
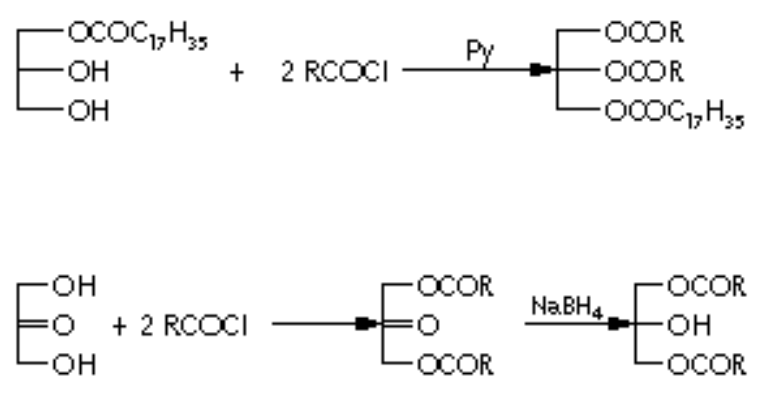

\section{Liquid part of fatty base}

The common low erucic rapeseed oil was used as a liquid part of fatty base. The content of individual triglycerides were determined by HPLC method [12]:

(LLLn) 3.4\%, (OLL + PLLn + LLL + StLnLn) 8.5\%, (OLL + OOLn + POLn + StLLn) 20.8\%, (OOL + POL + StOLn + StLL) 25.8\%, (OOO + POO + StOL) 30.9\%, (StOO + PStO) 5.2\%, (StStO + PStSt) 2.8\%, other triglycerides $0.8 \%$, polar subst. $1.5 \%$.

\section{Preparation of the two-component fatty bases}

The structured triacylglycerol was mixed with low erucic rapeseed oil at the temperature of $80^{\circ} \mathrm{C}$. Temperature $60^{\circ} \mathrm{C}$ was maintained for $5 \mathrm{~min}$. Cooling at the temperature of $0^{\circ} \mathrm{C}$ followed for a period of $60 \mathrm{~min}$, after which storing followed, at the temperature of $4^{\circ} \mathrm{C}$ [13]. Yield value was measured after 24 hours. The concentrations of structured fats were in a range $15-40 \% \mathrm{w} / \mathrm{w}$.

\section{Preparation of the three-component fatty bases}

These were prepared by mixing symmetrical and unsymmetrical triglycerides in ratio 2:1 with low erucic rapeseed oil at the constant concentration 30\% w/w. Prepared fatty bases: A- (2 parts CiStCi + 1 part CiCiSt), B- (2 parts LaStLa + LaLaSt), C- (MyStMy + MyMySt). The next way of preparation of fatty bases was identical.

The fatty base was characterised by following methods: melting point [14], solidification point [15], determining the solid fat content (SFC) by using the p-NMR method [13], determining the yield value at the arrangement plate-plate, using the instrument RheoStress RS 80 [16].

\section{Results and discussion}

\section{Properties of structured triacylglycerols}

In the following Table 1, melting points of synthetically prepared triacylglycerols are compared with the values that were reported in literature $[17,18]$. All structured triacylglycerols were obtained from 
2-propanol, using the crystallisation process.

Although the conditions of crystallisation were identical, it was found out, from the referred-to values, that the majority of the prepared structured triacylglycerols had the crystalline form beta or beta'. Only the value, which was found for the 1,2-dicaprinoyl-3-stearoylglycerol corresponded to the crystalline form alpha. The melting point of 1,3 -dilauroyl-2-stearoylglycerol $\left(50^{\circ} \mathrm{C}\right)$ is higher than the value $47^{\circ} \mathrm{C}[18]$.

\section{Properties of two-component model fatty bases}

The influence of molecular weight increase of structured unsymmetrical and symmetrical triacylglycerols has a considerable effect on the properties of the model bases. The concentration of structured triglycerides in fatty bases decreases from 30-40\% (dicaprinoylstearoylglycerols) to 15$30 \%$ (dimyristoylstearoylglycerols) in order to obtain stable fatty bases. For example the concentration $15-20 \%$ of dicaprinoylstearoylglycerols in fatty bases is insufficient.

\section{Melting point and solidification point of the model bases}

The values of the melting points and the solidification points increase with the growing molecular weight of structured triglycerides (Figures 1 and 2). The symmetry of structured triglycerides is a great influence on the solid-liquid system of fatty bases.

The melting points of model fatty bases comprising symmetrical structured triglycerides are higher than the melting points of model fatty bases comprising unsymmetrical structures with the exception of fatty bases comprising dimyristoylstearoylglycerols (Figure 1). The greatest differences of melting points were found out for fatty bases on the basis of 1,3-dilauroyl-2-stearoylglycerol and 1,2dilauroyl-3-stearoylglycerol (the differences $5-10^{\circ} \mathrm{C}$ ).

The solidification points of model fatty bases comprising symmetrical structured triglycerides are always higher than the melting points of model fatty bases comprising unsymmetrical structures (Figure 2). The differences correspond to approximately $8-10^{\circ} \mathrm{C}$ for fatty bases on the basis of structured symmetrical and unsymmetrical triglycerides. The influence of the growing molecular weight of structured triglycerides on solidification points was found greater than on melting points (Figures 1 and 2).

\section{The solid fat content of the model fatty bases}

For the comparison of the model bases SFC values, the $30 \% \mathrm{w} / \mathrm{w}$ concentration of the structured triacylglycerol in fatty base was chosen.

The effect of growing length of acyls in the structured triglycerides and the effect of symmetry of the structured triglyceride molecule are explicit (Figure 3). The SFC values of the fatty bases on the basis of unsymmetrical triglycerides are generally lower than those on the basis of symmetrical triglycerides. An exception is presented by the fatty bases containing dicaprinoylstearoylglycerols. The lowest solid fat content throughout the whole range of temperatures was measured in case of the model base comprising both dicaprinoylstearoylglycerols, on the contrary, the highest one in the case of the model base comprising 1,3-dimyristol-2-stearoylglycerol. The solid fat content of this base is very high $(12-18 \%)$ at the temperatures of $30-40^{\circ} \mathrm{C}$. The most considerable temperature 
dependence of the SFC was found for the model bases comprising both dicaprinoylstearoylglycerols. The solid fat content was zero at the temperature of $25^{\circ} \mathrm{C}$ already. On the contrary, the SFC is least temperature depend-ent in the case of the model bases comprising dimyristoylstearoylglycerols.

\section{Yield value of the model fatty bases}

A comparison of yield value dependence on the model fatty base temperature was carried out analogously as measuring of SFC profile at the structured triacylglycerol $30 \%$ concentration. The molecule symmetry effect of the structured triacylglycerols is primary. It influences the yield value of model fatty bases to the greatest measure. The influence of the growing molecular weight of structured triglycerides is secondary (Figure 4). It follows from the data that the yield value measurement could not have been carried out for all monitored fatty bases at the same temperatures. Depending on the increase of molecular weight of the structured triacylglycerol in the fatty base, the measurement had to be shifted from the starting temperature range of $5-15^{\circ} \mathrm{C}$ for the dicaprinoylstearoylglycerols to as high as $25-35^{\circ} \mathrm{C}$ for the 1,3 -dimyristoyl-2-stearoylglycerol. If these dependences are extrapolated, it can be expected that the zero yield values are achieved in the temperature range $15-45^{\circ} \mathrm{C}$ in dependence of growing structured triglyceride molecular weight.

\section{Properties of three-component model fatty bases - combination of unsymmetrical and symmetrical triacylglycerols}

We shall try to verify the hypothesis whether or not the monitored physical property of the mixed fatty bases is an additive property of the model (two-component) fatty base concentration. To this purpose, values of the physical quantities were found experimentally, on the one hand, and a calculation thereof was carried out, on the other hand.

The melting points of mixed fatty bases are always lower than are the calculated values thereof (Table 2), this value being simultaneously lower than the melting point of the symmetric triacylglycerol based fatty base. One may, thus, draw a conclusion, that mixed crystals are form-ed in the given case.

Contrary to the melting point, the calculated values of the solidification point for the mixed fatty bases $B$ a $C$ agree relatively well with the measured values. It would appear that one might quite simply explain the close correspondence of solidification points. A preferential nucleation of the component with the highest melting point (symmetrical triglycerides) takes place as the first one, with simultaneous formation of mixed crystals.

The SFC profiles of the mixed fatty bases confirm the results found for the simple fatty bases (Figures 3 and 5). The mixed base A reveals the most distinct decrease of the SFC values, being temperature dependent. On the contrary, the lowest temperature dependence reveals the mixed fatty base $C$ (Figure 5). The results found show that the degree of correspondence between the measured and the calculated SFC values for the mixed fatty bases is in general very small. The SFC values are not an additive property of the model (two-component) fatty base SFC. A series of factors is of importance here, mainly the conditions under which the crystallisation of triacylglycerols takes place during the samples tempering.

The results may be summarised into the conclusion that it is not possible to calculate parameters of physical properties of complicated fatty bases on the basis of knowledge of physical properties of 
two component (very simple) fatty bases.

\section{CONCLUSION}

The molecular weight and the molecule symmetry of the structured triacylglycerides studied have a basic effect on the model fatty base properties. Suitable ratios of structured diacylstearoyglycerols and low erucic rapeseed oil were found. The knowledge of this ratio is of important for the application of the fatty base formulae.

It was found out in the case of the mixed model bases based on symmetrical and unsymmetrical structured triacylglycerols that the monitored physical properties of the model three component fatty bases are not an additive property of the model two component fatty bases, generally.

\section{REFERENCES}

1. FRITSCHE J, STEINHART H (1997). Trans fatty acid content in German margarines. Fet/Lipid, 99: 214-7.

2. MAG TK (1994). Margarine oils, blends in Canada. Inform, 5: 1350-3.

3. LANSBERGEN AJ, SCHIJF R (1991). Edible fats. Eur Pat Appl, 455: 278 A2.

4. MAGUIRE J (1995). An edible fat blend. UK Pat Appl, 2: 281-304.

5. HUINZINGA H, SASSEN CL, VERMAAS LF, SCHUR P (1996). Margarine fat blend and plastic w/o emulsion spread comprising this fat blend. WO, 96/19115.

6. WARD J (1985). Low-fat spread and process. USA Pat, 4: 533-61.

7. CHANDRAN DV, BHATANAGAR RK (1968). A method for synthesis of alpha-monoricinolein. J Am Oil Chem Soc, 45: 581-2.

8. MANK APJ, WARD JP, DORP VAN DA (1976). A versatile, flexible synthesis of 1,3-diglycerides and triglycerides. Chem Phys Lipids, 16: 107-14.

9. BARRY PJ, CRIG BM (1955). Glyceride synthesis - I. Synthesis of symmetrical diglycerides from dihydroxyacetone and allyl alcohol. Can J Chem, 33: 716-20.

10. BENTLEY PH, MCCRAE W (1970). An efficient synthesis of symmetrical 1,3-diglycerides. J Org Chem, 35: 2082-3.

11. RANNY M (1987). Thin-layer chromatography with flame ionization detection. Academia Praha: 136-47.

12. PÁNEK J, POKORNY J, DAVÍDEK J (1989). Determination of the oxidized products in foodgrade vegetable oils by HPLC. Czech J Food Sci, 7: 253-61.

13. IUPAC STANDARD METHODS FOR THE ANALYSIS OF OILS, FATS AND DERIVATIVES (1987). Solid contents determination in fats by NMR. 7th ed. Oxford: Blackwell Sci. Publ. 
14. DGF EINHEITSMETHODEN (1987). C-IV 3b Flie3punkt und Tropfpunkt. Stuttgart: Wissensch Verlages $\mathrm{mbH}$.

15. IUPAC STANDARD METHODS FOR THE ANALYSIS OF OILS, FATS AND DERIVATIVES (1987). Determination of cooling curve of fats. 7th ed. Oxford: Blackwell Sci. Publ.

16. STERN P, CMOLÍK J (1981). Rheological study of sunflower margarine. Fette Sifen Anstrichm, 83: 144-7.

17. CARTER MGR, MALKIN T (1939). An X-Ray and thermal examination of the glycerides. Part. VII. Unsymmetrical mixed triglycerides. J Chem Soc, 1518-21.

18. MALKIN T, MEARA ML (1939). An X-Ray and thermal examination of the glycerides. Part VI. Symmetrical mixed triglycerides. J Chem Soc, 1141-4.

Illustrations

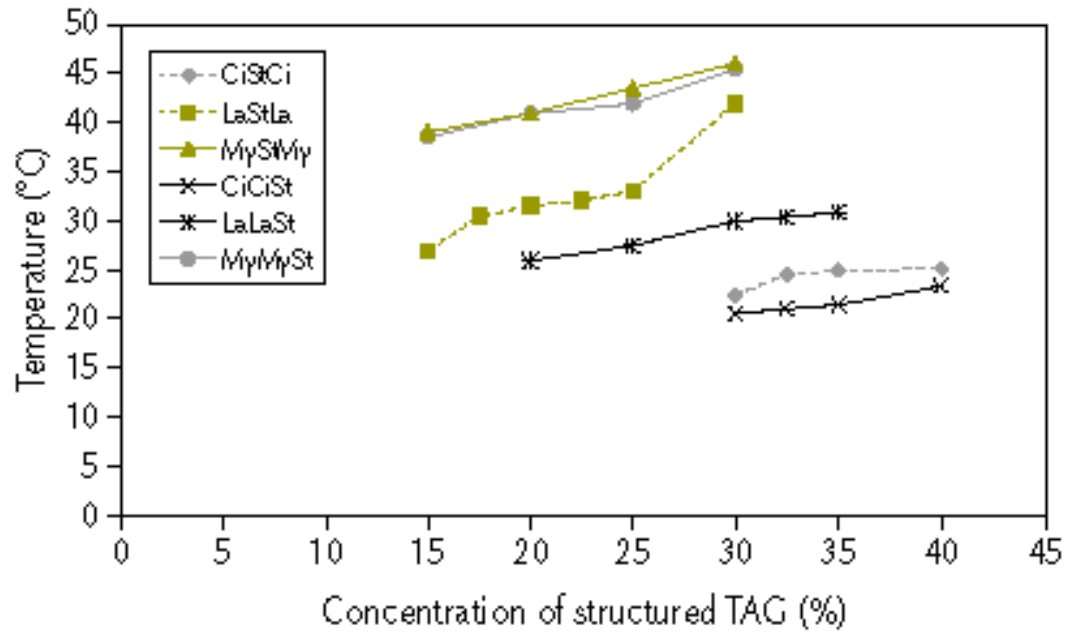

Figure 1. The dependence of fatty base melting point on the concentration of structured triglycerides. 


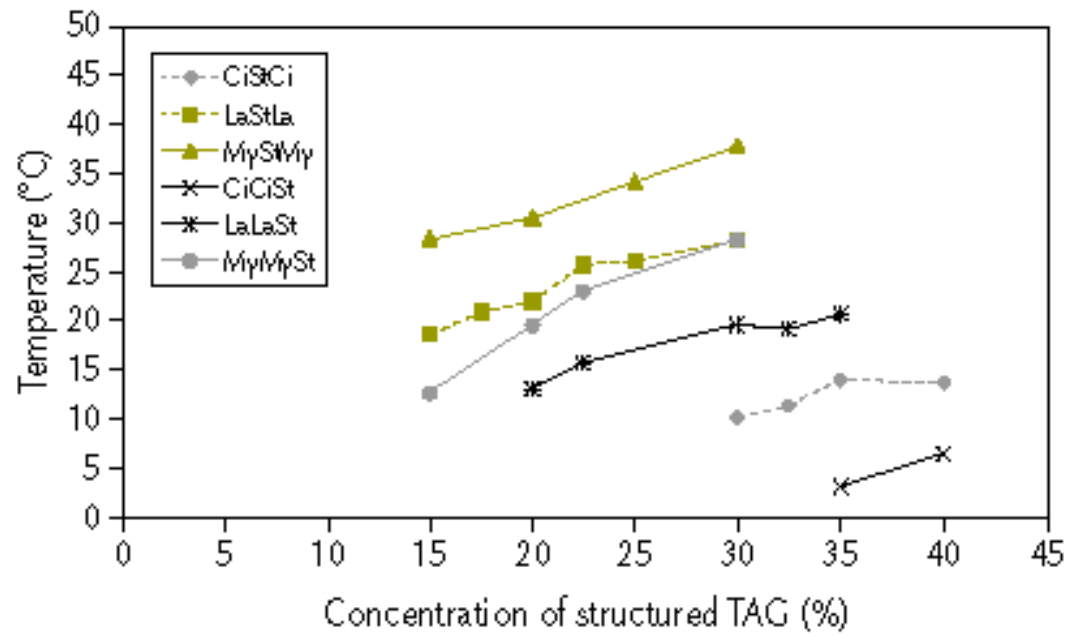

Figure 2. The dependence of fatty base solidification point on the concentration of structured triglycerides.

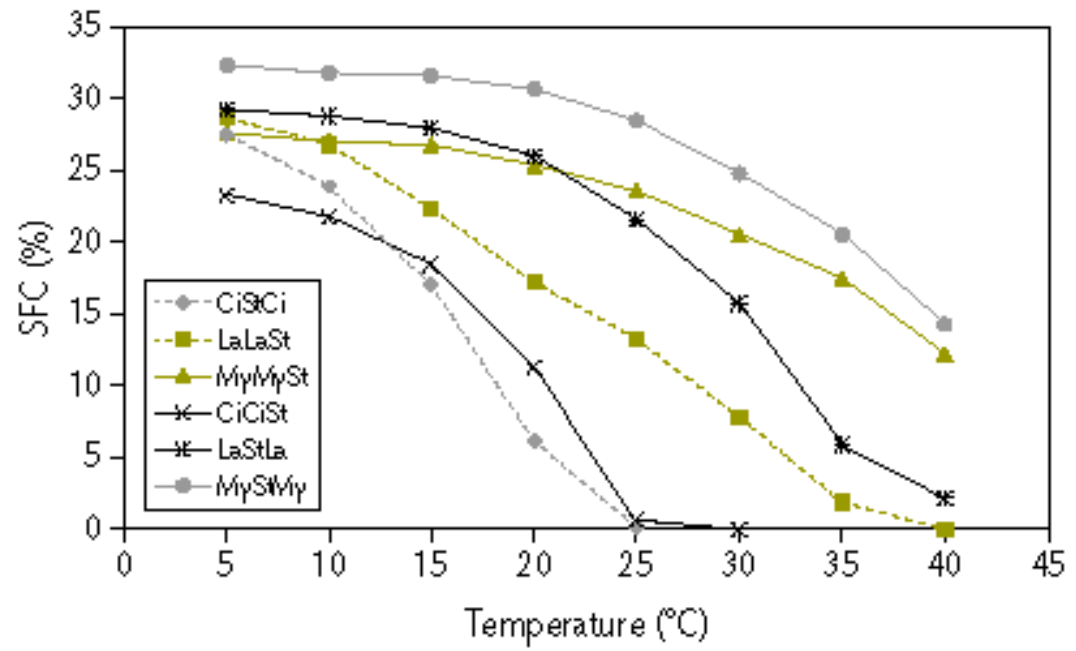

Figure 3. The dependence of two-component fatty base SFC on temperature.

Concentration of structured triglycerides $30 \% \mathrm{w} / \mathrm{w}$. 


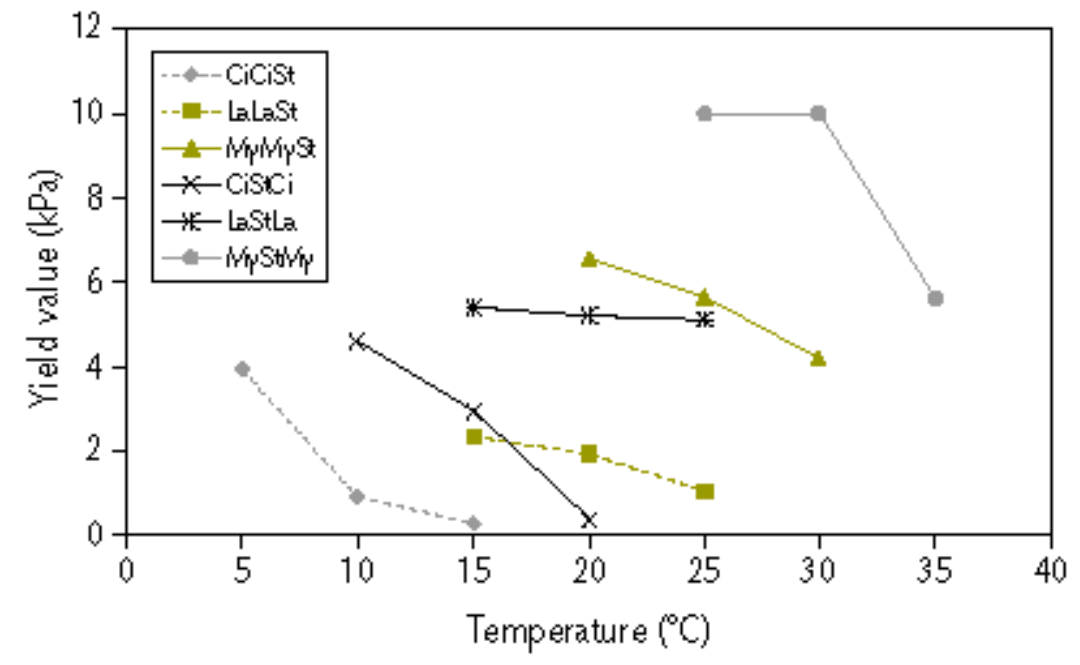

Figure 4. The dependence of two-component fatty base yield value on temperature. Concentration of structured triglycerides $30 \% \mathrm{w} / \mathrm{w}$.

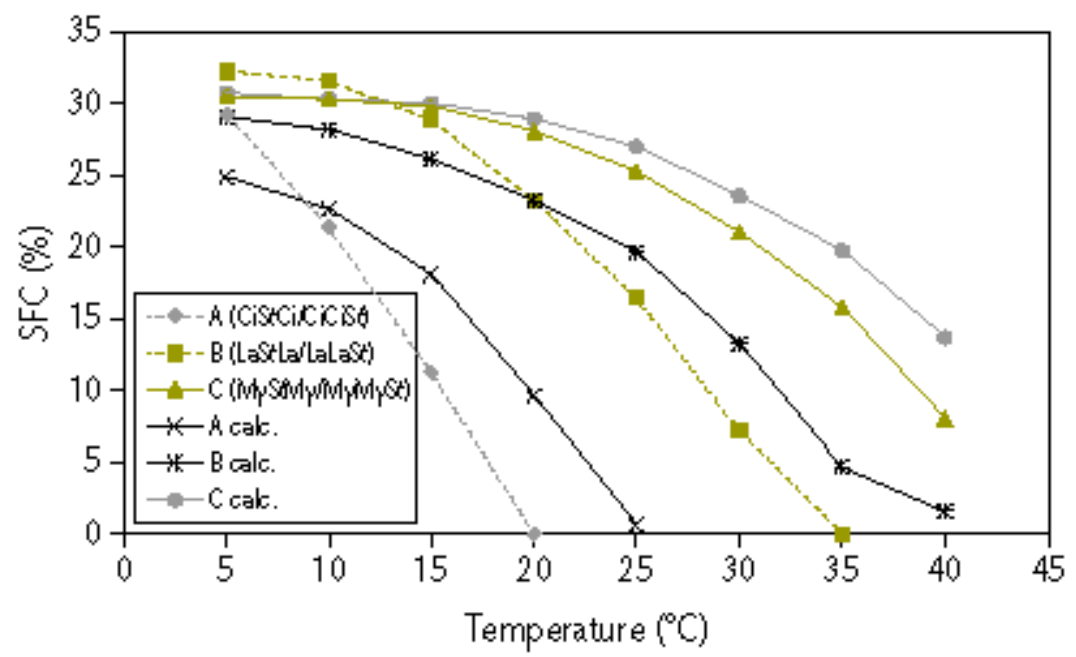

Figure 5. The dependence of three-component fatty base SFC on temperature. Concentration of structured triglycerides $30 \% \mathrm{w} / \mathrm{w}$. 
Table 2. Melting points and solidification points of thre component fatty bases.

\begin{tabular}{l|c|c|c|c}
\multirow{2}{*}{ Fatty base } & \multicolumn{2}{|c|}{$\begin{array}{c}\text { Melting point [ } \mathrm{C} \text { C] } \\
\text { Calc. value }\end{array}$} & $\begin{array}{c}\text { Solidification point ['C] } \\
\text { Exp. value }\end{array}$ \\
\hline Calc. value \\
B & 15.4 & 21.8 & 7.9 & - \\
C & 32 & 38 & 26 & 25.3 \\
& 42.5 & 45.8 & 34.1 & 34.8
\end{tabular}

Table 2. Melting points and soldification points of three component fatty bases.

\begin{tabular}{l|c|c|c|c}
\multirow{2}{*}{ Fatty base } & \multicolumn{2}{|c|}{$\begin{array}{c}\text { Melting point [ } \mathrm{C} \text { C] } \\
\text { Exp. value }\end{array}$} & \multicolumn{2}{c}{$\begin{array}{c}\text { Solidification point [' C] } \\
\text { Cxp. value }\end{array}$} \\
\hline A & 15.4 & 21.8 & 7.9 & - \\
B & 32 & 38 & 26 & 25.3 \\
C & 42.5 & 45.8 & 34.1 & 34.8
\end{tabular}

